Revista Transgressões: ciências criminais em debate, v. 5, n. 2, Outubro 201\%, Natal/RN

\title{
MULHERES E CRIMINALIDADE: ASPECTOS DE UMA INCLUSÃO ENVIESADA
}

\section{Sabrina Lima Silva}

Possui graduação em Serviço Social pela Universidade Federal do Rio Grande do

Norte.

E-mail: sabrinalimass32@gmail.com

\section{RESUMO}

No Estado do Rio Grande do Norte, houve um aumento de $28 \%$ no número de mulheres assassinadas por envolvimento em condutas ilícitas, no período correspondente aos meses de Janeiro a Junho do ano de 2017, em comparação com o mesmo período do ano passado. Tal fenômeno nos estimula a pesquisar quais seriam as principais causas para o crescente índice de femícidios no Estado, estabelecendo um contrapondo entre gênero e criminalidade, avaliando o primeiro semestre do ano em curso.

PALAVRAS-CHAVE: Femicídio. Desigualdade de gênero. Criminalidade.

Os ninguéns: os filhos de ninguém, os dono de nada. Os ninguéns: os nenhuns, correndo soltos, morrendo a vida, fodidos e mal pagos:

Que não são, embora sejam.

Que não falam idiomas, falam dialetos.

Que não praticam religiões, praticam superstições.

Que não fazem arte, fazem artesanato.

Que não são seres humanos, são recursos humanos.

Que não tem cultura, têm folclore.

Que não têm cara, têm braços.

Que não têm nome, têm número.

Que não aparecem na história universal, aparecem nas páginas policiais da imprensa

local.

Os ninguéns, que custam menos do que a bala que os mata.

(Eduardo Galeano) 


\section{INTRODUÇÃO}

No ano de 2017, o Rio Grande do Norte alcançou, nos seis primeiros meses do ano em curso, a marca de 1.000 (um mil) homicídios. De acordo com o último levantamento, referente ao mês de Junho, já se contabiliza 1198 (mil cento e noventa e oito) Condutas Violentas letais e intencionais (CVLI), totalizando um aumento de $21,9 \%{ }^{38}$.

Seguindo estes dados, também é vertiginoso o número de mulheres assassinadas por causas diversas. Os chamados feminicídios ${ }^{39}$, tiveram redução de $10 \%$ de acordo com o mesmo período do ano passado. Já os femicídios, sofreu aumento de $28 \%$ se comparado com o mesmo período do ano passado.

De acordo com os dados fornecidos pela SESED, a maior causa de mortes de mulheres no Estado é o envolvimento com o tráfico de drogas, com 51,6\%, seguido de violência doméstica e familiar com $21,9 \%$ dos casos. A violência patrimonial alcança $14,1 \%$ dos casos, a interpessoal $9,4 \%$ e as causas de mortes que não tiveram motivos confirmados são de $3,1 \%$.

Diante das estatísticas, é despertado o interesse de averiguar e refletir quais as reais motivações está por trás desses números. Quais fatores são essenciais para que o Estado do Rio Grande do Norte tenha um alto índice de CVLI, no que tange também ao número de mulheres assassinadas.

Neste sentido, a presente pesquisa está dividida em duas sessões, de modo que, a primeira dispõe sobre $1-\mathrm{O}$ empoderamento: rompimento com as amarras da opressão de gênero alçada ao sexo feminino, no qual será feita uma análise da entrada da mulher no mercado de trabalho, em sua primeira subsessão, intitulada inserção da mulher no mundo do trabalho. Na segunda subsessão será analisada a entrada da mulher na criminalidade, com o recorte para o Estado do Rio Grande do Norte. A última sessão será realizada as conclusões do trabalho, apontando soluções palpáveis para enfrentar as reais causas do crescente número de femícidios.

\footnotetext{
${ }^{38}$ Os dados são da Secretaria de Segurança Pública e da Defesa Social do Estado do Rio Grande do Norte (SESED).

${ }^{39}$ Femicídio refere-se a conduta violenta letal e intencional pelo fato da mulher pertencer ao sexo feminino. Já o femicídio, e o homicídio de mulheres por causas diversas que não seja relacionada ao fato de ser mulher.
} 


\section{EMPODERAMENTO: ROMPIMENTO COM AS AMARRAS DA OPRESSÃO DE GÊNERO ALÇADA AO SEXO FEMININO}

\subsection{A INSERÇÃO DA MULHER NO MUNDO DE TRABALHO}

$\mathrm{Na}$ atualidade, quando se discute sobre a luta das mulheres por direitos iguais, o termo empoderamento é muito utilizado. Esta expressão pode adquirir inúmeros significados em contextos diferentes, no entanto, para o movimento feminista ele tem um sentido diferenciado. De acordo com Sandenberg (2009), "para as feministas latinoamericanas, em especial, o objetivo maior do empoderamento das mulheres é questionar, desestabilizar e, por fim, acabar com o a ordem patriarcal que sustenta a opressão de gênero".

Para as mulheres, este termo é sinônimo de autoafirmação, de resistência, de conquista e de libertação das amarras da opressão das condições de subalternidade alçadas para o sexo feminino. É por em questionamento as formas de submissão socialmente construídas sobre o que é "ser mulher" e quais seriam o comportamento adequado a ser seguido $^{40}$.

É notório o crescimento do movimento feminista e o empoderamento feminino no século XXI. Muitas foram as conquistas com o passar dos anos, tais como direito a votar e ser votada, ao ensino, ao ocupar cargos de instância superior e as legislações que protegem os direitos das mulheres ${ }^{41}$. Sabe-se que apesar do avanço, a desigualdade de gênero ainda permeia as relações, visto que, uma sociedade livre de relações desiguais de poder não é possível em um modo capitalista de produção.

Nesta perspectiva, (MARX, 1982), afirma que com o advento da sociedade capitalista, e o emprego das máquinas, a força não é mais essencial para produção, esta passa a ser substituída pela necessidade de flexão. Deste modo, as mulheres começam a serem absorvidas pela necessidade de produção em massa, bem como de todos os membros da família auferir renda.

Não obstante, e a necessidade da mão de obra, as mulheres passam cada vez mais a sair do âmbito privado, restrito ao cuidado da casa e dos filhos, e passa a se inserir no âmbito

\footnotetext{
${ }^{40}$ De acordo com (CAMURÇA E GOUVEIA, 2004), homens e mulheres possuem em seus corpos diferenças biológicas. A partir das observações das diferenças sexuais, cria-se representações do que é ser homem e do que é ser mulher, ou seja, as chamadas representações de gênero.

${ }^{41}$ Sobre as legislações que versam sobre os Direitos das Mulheres em seus relacionamentos íntimos temos a Lei 11.340, a Lei Maria da Penha, reconhecida pela ONU como uma das legislações mais eficaz no combate a violência doméstica, bem como a Lei 13.104 que prevê o feminicídio como circunstância qualificadora do crime de homicídio.
} 
público e no mercado de trabalho, nas empresas capitalistas, ou no mercado informal de trabalho. (KOLONTAI, 1979, p. 17) coaduna com esse pensamento, ao afirmar que:

\begin{abstract}
As relações de produção, que durante tantos séculos mantiveram a mulher trancada em casa e submetida ao marido, que a sustentava, são as mesmas que, ao arrancar as correntes enferrujadas que a aprisionavam, impelem a mulher frágil e inadaptada à luta do cotidiano e a submetem à dependência econômica do capital. A mulher ameaçada de perder toda a assistência, diante do temor de padecer privações e fome, vê-se obrigada a aprender a se manter sozinha, sem o apoio do pai ou do marido. A mulher defronta-se com o problema de adaptar-se rapidamente as novas condições de sua existência, e tem que rever imediatamente as verdades morais que herdou de seus avós. Dá-se conta, com assombro, de toda inutilidade do equipamento moral com que a educaram para percorrer o caminho da vida. As virtudes femininas passividade, submissão; doçura - que lhe foram inculcadas durante séculos, torna-se agora completamente supérfluas, inúteis e prejudiciais.
\end{abstract}

Por esta ótica, infere-se que o modo de produção capitalista necessitando da produção em massa, absorveu a mão de obra feminina de forma enviesada, posto que, estas amargavam menores salários. De acordo com os apontamentos de (RODRIGUES ET AL, 2015) as mulheres entram na indústria têxtil devido aos baixos salários dos homens que não conseguia atender a necessidade da família, deste modo, esta mão de obra era desvalorizada e, portanto altamente lucrativa para seu empregador.

Todavia, ao perceber abrupta entrada das mulheres no mundo do trabalho (KOLONTAI, 1979), evidencia que o capitalismo contemporâneo exige que estas se pareçam mais com os homens do que com a mulher do passado. E que, para aquelas que não conseguem se adaptar a nova realidade não há espaço.

Neste sentido, também é evidenciado a divisão sexual do trabalho neste período, visto que, as mulheres se inseriam na industria têxtil, e que, por mais que estas passassem a se inserir no âmbito público, ainda ficavam imbuídas da responsabilidade de cuidar dos filhos e das atividades doméstica no âmbito privado. Nesta vertente, evidencia-se que as mulheres foram absorvidas rapidamente pelas industrias capitalistas, mas que sua mão de obra era muito lucrativa, visto que, estas eram impelidas pelas necessidades, mas essa inserção é precarizada desde o início.

No que tange ao século XXI, realizando um recorte da sua segunda década, vive-se em uma conjuntura política e econômica de retrocesso, não só não Brasil, mas nos países Latinoamericanos. Em algumas nações do continente, como por exemplo, na Argentina, o governo defende claramente uma política atentatória dos direitos da classe trabalhadora, com 
altos índices de desemprego e aumento da inflação. Como consequência disso, temos o avanço do neoliberalismo ${ }^{42}$, com um estado mínimo para o social e máximo para o capital.

O resultado da expansão do Estado Neoliberal é o desemprego estrutural, vínculos de trabalho cada vez mais precários, jornadas exaustivas de trabalho, baixa remuneração e o aumento do exercito industrial de reserva ${ }^{43}$. Com isto, cresce miséria social o acirramento da desigualdade entre classes.

Neste viés, por todo contexto de opressão vivenciado pelas mulheres ao longo de séculos, e ser fruto das relações desiguais de poder, esse processo de retrocesso evidencia ainda mais um fenômeno chamado de "feminização da pobreza" 44 . Historicamente por terem ficado restrita a tarefas domésticas, bem como por sofrerem preconceitos para desempenhar algumas atividades consideras de mulheres e com isto remunerações menores. Neste sentido, por feminização da pobreza, infere-se que:

\begin{abstract}
Mais especificamente, é um aumento na diferença de níveis de pobreza entre as mulheres e os homens, ou por um lado, entre os domicílios chefiados por mulheres, e, por outro lado, aqueles chefiados por homens ou casais. O termo também pode ser usado para significar um aumento da pobreza devido às desigualdades entre homens e mulheres, embora prefiramos chamar a isto a feminização das causas da pobreza. (MEDEIROS E COSTA, 2008, P. 01).
\end{abstract}

Por esta ótica, de acordo com os dados do IBGE, coletados no último Censo no ano de 2010, o rendimento médio de homens com 16 anos ou mais ocupados é de R\$1.139,71 (mil cento e trinta e nove reais e setenta e um centavos). Já o rendimento médio das mulheres com 16 anos ou mais ocupadas é de $\mathrm{R} \$$ 938,10 (novecentos e trinta e oito reais e dez centavos).

Somado a este fator, também temos o aumento das mulheres que são chefes de família. Ainda de acordo com o último Censo do IBGE, 38,7\% dos domicílios são chefiados por mulheres. Comumente, estas enfrentam dupla jornada, ou seja, além do trabalho fora de casa, ainda possui as atividades doméstica para desempenhar, bem como o cuidado com os

\footnotetext{
${ }^{42}$ De acordo com os apontamentos de Behring (2007), o Neoliberalismo é uma doutrina para sair da crise do pós-guerra na década de 1970. De acordo com a autora, foram cinco as proposições básicas propostas, tais como: o rompimento dos poderes dos sindicatos de trabalhadores e o controle da moeda; a diminuição dos gastos sociais e a regulação da economia; estabilidade monetária como meta suprema; contenção do gaste social e a manutenção da taxa de desemprego; diminuição de impostos sobre os rendimentos mais altos; desmonte de direitos sociais.

${ }^{43}$ Conceito desenvolvido por (MARX, 1982), em sua crítica a economia política em sua obra "O Capital”, o qual se refere à população massiva sobrante sem trabalho, uma espécie de fila de espera, nesta caso, por mais que as condições de trabalho sejam precárias e um/a trabalhador/a venha recusar o vínculo empregatício, terá outra gama de pessoas disposto a aceitá-lo.

${ }^{44}$ Segundo os estudos de Costa et al (2005), 70\% das pessoas pobres do mundo são mulheres. Tal fator acontece pelo fato da disparidade de gênero, e atinge principalmente aquelas mulheres que são chefes de família.
} 
filhos menores. Sabe-se que as mulheres são maioria no nível superior, no entanto, elas amargam alto índice de desemprego e menores rendimentos.

Deve-se ponderar que o maior grau de risco social das mulheres pobres que além de ter que arcar com o próprio sustento, tem que priorizar também o da sua família, associa-se as expectativas limitadas de futuro e faz com que possibilidades de "ganhos fáceis" e mais lucrativos a curto prazo, oriundos das atividades criminosas sejam almejados como possibilidade. (CHERNICHARO, 2014).

Concorda-se que com o contexto de dupla ou até tripla jornada, baixa remuneração, e vínculos empregatícios precários, é evidente que estas mulheres, principalmente aquelas que pertencem à classe trabalhadora, buscam formas de auferir renda para suprir suas necessidades mais básicas, bem como a de seus filhos. Desta forma, estas mulheres são absorvidas de forma enviesada pela criminalidade.

De todo modo, que a pobreza e a desigualdade de classe e gênero não podem ser vistas como um fator determinante para o envolvimento com atividades ilícitas, entretanto, pode ser observada como um fator que impele a classe que vive do trabalho a se envolver com ações criminosas.

\section{2 . SELETIVIDADE PENAL E DESIGUALDADE DE GÊNERO}

Diante do processo histórico subalternidade e dominação destinada ao sexo feminino pela construção social de gênero, as mulheres são mais suscetíveis ao desemprego, aos vínculos empregatícios precários e baixa remuneração. Isto posto, também são impelidas a miséria, fome e negação de direitos.

Por este viés, no último século ocorreu uma drástica mudança no comportamento feminino, que passou a deixar de habitar exclusivamente o âmbito privado, restrito as tarefas domésticas e ao lar, para habitar o âmbito público nas empresas capitalistas, espaço de decisões políticas, universidades, entre outros.

Em consonância a essa mudança de comportamento, também é crescente o número de mulheres envolvidas com a criminalidade, e como consequência desse envolvimento, há um expressivo aumento de mulheres em situação de privação de liberdade, como também assassinadas.

Anteriormente as mulheres eram reclusas por crimes relacionados ao sexo, ou a sua condição de subalternidade, tais como crimes passionais, infanticídio, prostituição, aborto, 
como aponta Del Omo (1996). No entanto, na sociedade capitalista moderna as mulheres são reclusas, principalmente por crimes relacionados ao tráfico de drogas.

No entanto, seguindo esta linha de raciocínio a autora discute teorias para o aumento do envolvimento da mulher com o crime, neste sentido ela aponta três hipóteses distintas para o aumento do número de mulheres transgressoras.

Del Omo (1996), traz a baila a teoria da nova criminalidade, (New Female Criminal), a qual sugere que a libertação feminina aponta para que a mulher, ao transgredir está adquirindo um papel destinado anteriormente apenas aos homens.

A segunda teoria refere-se à necessidade econômica (teoria de La nececidad econômica), a qual sugere que na medida em que a mulher tem buscado sua emancipação, ela precisa arcar com suas anseios econômico,e por isso não pode assumir uma atitude paternalista e dependente do homem.

A terceira teoria refere-se à oportunidade econômica (teoria de las oportunidades económicas), a qual sugere que a criminalidade feminina é um produto do acesso mais amplo da estrutura da mulher a economia, ou seja, a participação da mulher nas atividades econômicas exerce forte influência na conduta criminosa.

Concorda-se com Del Omo (1996), quanto as duas últimas hipóteses levantadas, posto que é perceptível que as mulheres enxergam na criminalidade uma forma de ascensão social, possibilidade de renda e de ganhos maiores, sem a necessidade de jornadas exaustivas de trabalho ou vínculos empregatícios precários, bem como a manutenção do cuidado com os filhos e as atividades domésticas sem a necessidade de se ausentar do lar.

No entanto, ao se referir a teoria da nova criminalidade feminina, pensa-se que a mulher vem ocupando cada vez mais espaços, e dentre estes novos campos de inserção o crime também aparece como tal. Deste modo, não seria assumir um papel masculino, ou uma disputa entre sexo, mas uma forma de adentrar em um espaço passível de "inclusão" 45 .

Ao negar que a mulher é incapaz de cometer uma transgressão penal, nega-se toda a trajetória das conquistas dos direitos da luta feminista, Almeida (2001), adverte que negar esta capacidade de uma mulher cometer uma ação pública, mesmo sendo uma violência, é uma forma de submete-la a ordem do âmbito doméstico, de mantê-la sob a ordem moral criada por homens de que o espaço da mulher é casa e não da rua.

Como desdobramento do envolvimento com o crime tem-se o encarceramento em massa e o aumento no índice de assassinatos. Realizando um recorte de gênero, esse número é

\footnotetext{
${ }^{45}$ De acordo com os estudos de (MARTINS, 1997), o modo de produção capitalista exclui, marginaliza para poder incluir de outra forma.
} 
ainda mais preocupante, visto que, de acordo com o INFOPEN, o número de mulheres reclusas aumentou 567\% em uma década (2000 a 2014). Do total da população carcerária do país, corresponde apenas $6,4 \%$ da população, no entanto, no mesmo período, o número de reclusão de homens aumentou $220 \%$.

No que concerne aos dados sobre homicídios por armas de fogo (HAF), de acordo com os dados do Mapa da violência, 94,4\% das pessoas assassinadas no Brasil são do sexo masculino, sendo 6,6\% das vítimas mulheres. Apesar do estudo ter sido divulgado neste ano, os dados são de 2014.

Contudo, no que tange o Estado do Rio Grande do Norte, sabe-se que dentro do universo de mil condutas violentas letais e intencionais no período de janeiro a março de 2017, 5,3\% das vítimas eram mulheres, no entanto, esse número tem aumentado em uma proporção maior do que o assassinato de homens. Enquanto o número de homicídios aumentou $21 \%$, o número de assassinatos de mulheres teve o percentual de $28 \%$.

Ainda de acordo com os dados oficiais da SESED, a maioria dos assassinatos de mulher no primeiro período do ano de 2017 está ligado ao envolvimento com o tráfico de drogas, cerca de 51,6\%. A de se considerar também que, não há uma cultura de investigação por parte dos assassinatos ocorridos em massa, principalmente no quis diz respeito a estrutura do Instituto Técnico e Científico de Perícia (ITEP), do Estado do Rio Grande do Norte. A estrutura do Instituto médico legal não suporta a quantidade de corpos oriundos das condutas violentas letais e intencionais, que não raro, registra cerca de 30 assassinatos por final de semana no Estado.

Deste modo, os crimes que são investigados são aqueles revestidos pelo clamor social de justiça punitiva. Para aqueles crimes que não possuem tanta repercussão midiática, são relacionados ao tráfico de drogas ou rivalidade entre facções. Assim, as pessoas assassinadas são comumente ligadas a criminalidade e se evoca o estigma de que a execução de homens e mulheres envolvidos com atividades ilícitas é um bom serviço prestado a sociedade.

Seguindo esta linha de raciocínio, não se espera que pessoas do sexo feminino sendo estigmatizadas de seres dóceis e frágeis não e envolvam com a criminalidade, invocando do passado o pensamento de Lombroso e Ferrero de que a mulher possui imobilidade e passividade e portanto, obedece mais as leis. Tal modelo, verticaliza, hierarquiza e exclui aquelas que não se adaptam, (Espinosa, 2004). Por esta ótica, temos um julgamento moral do comportamento feminino que corrobora com o fato desses femicídios não sejam investigados. 
Para (CHERNICHARO, 2014), as mulheres não são mais propensas a delinquir, no entanto a sua criminalidade é mais "visível”, posto que a sua condição socialmente construída pelo estereótipo de gênero e a sua condição de pobreza faz com que elas sejam candidatas pré-selecionadas para responder pelo delito de tráfico de drogas.

Neste sentido, avaliando o contexto da famigerada "Guerra ao tráfico de drogas", aponta-se o tráfico de substâncias ilícitas como o principal fator para o extermínio da população, principalmente a juventude do Estado Norte-Riograndense. Neste prisma, observase que:

\begin{abstract}
Os alvos nessa guerra são os mais vulneráveis dentre os produtores, comerciantes e consumidores das drogas proibidas; os "inimigos" nessa guerra, são seus produtores, comerciantes e consumidores pobres, não brancos, marginalizados, desprovidos de poder. (KARAM, 2010, p. 171).
\end{abstract}

No que se refere ao sistema carcerário feminino, o Brasil possui a $5^{\mathrm{a}}$ maior população carcerária do mundo. Cerca de $58 \%$ das mulheres em situação privação de liberdade no país cometeram delitos relacionados ao tráfico de drogas. Já no Rio Grande do Norte, o total de mulheres que cumpre pena no regime aberto, semiaberto e fechado é de aproximadamente 520, de acordo com os dados fornecidos pela Secretaria de Estado da Justiça e da Cidadania (SEJUC).

Apesar de saber que a grande parcela desse total cometeu algum delito relacionado ao tráfico de substâncias ilícitas, a SEJUC, responsável pela administração penitenciária, não possui estes dados precisos sobre o quantitativo de mulheres que cometeram cada delito.

Por este ângulo, (Karam, 2010) aponta que como resultado da guerra as drogas, temos violência, encarceramento e morte, principalmente da população mais suscetível a riscos sociais. Assim sendo, pelo contexto de violação histórica destinada as mulheres, estas são previamente selecionadas pelo sistema penal para serem punidas, bem como são alvos mais fáceis de serem exterminadas.

Realizando um recorte interseccionalidade ${ }^{46}$, as mulheres assassinadas no estado são em sua maioria jovens. Os assassinatos ocorrem em bairros mais populares da capital. Os dados da SESED não analisam questões relacionadas a raça/etnia e classe social, no entanto, o perfil da mulher vítima femicídio, 68,8\% das tinham idade entre 12 e 29 anos. 7,8\% tinha entre 30 e 34 anos e $23,4 \%$ tinha entre 35 a 64 anos.

De acordo com o terceiro boletim de mortes matadas de mulheres do Observatório da Violência Letal e Intencional, o qual faz um recorte de gênero nas vítimas de assassinatos no

\footnotetext{
${ }^{46}$ De acordo com os estudos de Hirata (2014), o termo é usado para designar dependência de gênero, classe e raça, ou seja, quando há mais de um sistema de opressão.
} 
estado entre os meses de janeiro a março de $2017,59,05 \%$ eram pardas, $27,71 \%$ eram brancas e $13,11 \%$ eram negras. O aponta ainda que a maioria das vítimas possuía baixo grau de instrução, como também não possuíam renda mensal fixa.

Diante do exposto, infere-se que o crescente número de mulheres envolvidas com a criminalidade no Estado do Rio Grande do Norte, e como consequência adesão tem-se o encarceramento em massa e o aumento no número de assassinatos, tem um perfil préselecionado.

Estas mulheres são provenientes da classe trabalhadora, solteira, possui baixo grau de instrução, atividade ignorada, ou sem remuneração. Tais dados coadunam com os apontamentos dos estudos das autoras Chernicharo (2014), Del Omo (1996), Karam (2014), que evidenciam a seletividade do sistema de justiça, bem como do extermínio da população, principalmente da juventude pobre e negra.

\section{CONCLUSÃO}

Diante das análises realizadas nesta pesquisa bibliográfica, compreende-se que no Estado do Rio Grande do Norte houve um significativo aumento da violência, principalmente a mais nefasta, a conduta letal e intencional. Entendemos que massacres pré-anunciados como o que ocorreu em Alcaçuz, com um número expressivo de mortes serviram para alavancar as estatísticas no número de homicídios no Estado.

Deste modo, com o aumento da violência e como consequência deste fator a disparada no índice de assassinatos, desencadeia também o número de mulheres envolvidas com a criminalidade, desembocando no aumento no número de encarceramentos femininos, bem como com o de femícidios.

Fazendo um recorte histórico, sabe-se que a entrada da mulher no mercado de trabalho ocorreu de forma abrupta, posto que estas foram educadas a serem dóceis, frágeis e ficarem responsáveis pelo cuidado dos filhos e do lar. No entanto, no século XX, estas se vêm obrigada a buscar seu próprio sustento, como também o dos seus filhos, se tornando independente da figura masculina, como apontado nos estudos de (KOLONTAI, 1989) e (DEL OMO, 1996).

Como consequência dessa inserção abrupta, do papel de subalternidade destinado a mulher, temos expressão da questão social como a feminização da pobreza, acirrada ainda 
mais pela atual conjuntura política que vive os países da América Latina, entre eles o Brasil, que viu sua recente democracia abalada por um golpe que afastou definitivamente uma presidenta democraticamente eleita Dilma Rousseff, e colocou no poder um presidente ilegítimo, Michel Temer, que defende claramente uma política neoliberal atentatória dos direitos da classe trabalhadora.

Com a fragilidade oriunda da política do país, bem como o retrocesso de conquistas de direitos da população mais vulnerável, acirra ainda mais a desigualdade social e a necessidade de encontrar novos meios de auferir renda para suprir as necessidades mais básicas, principalmente para as mulheres pobres e negras que já possui um contexto histórico de opressão e encontram-se na base da pirâmide social.

Não obstante, essa subalternidade também é evidenciada na criminalidade, posto que pela construção as mulheres ainda integram pequenos espaços no tráfico de drogas, como "mulas", aviões e "esticas". Posto isto, as pessoas selecionadas para serem criminalizadas por exercerem crimes relacionados ao tráfico de drogas são as que ocupam posições inferiores, já que os grandes traficantes conseguem não ser penalizados. Também são estas que são selecionadas para serem punidas com a privação da sua liberdade ou com a sua vida.

Enxergando que as mulheres se constituem em um segmento vulnerável, principalmente a mulher oriunda da classe trabalhadora e negra, pois a violência atinge mulheres de forma diferenciada conforme os sistemas de opressão a que elas estão submetidas, é necessário realizar políticas públicas para combater esse índice crescente de mulheres envolvidas com a criminalidade.

Neste sentido, é necessário investimento em ações voltadas para autonomia financeira e política das mulheres, pois há um crescente número de domicílios sendo chefiado exclusivamente por mulheres. Para tanto, são necessários dados atualizados sobre a situação econômica das potiguares, que devem ser gerados através de pesquisas.

O Estado ainda amarga um visível retrocesso no campo da igualdade de gênero. Por isto, devem ser pensadas políticas integradas e transversais, de modo que, abranjam segurança, com o fortalecimento da rede de proteção a mulher, assistência social, com a inserção nos programas de transferência de renda, educação e saúde, com o intuito de garantir os direitos sociais previstos em constituição. 


\section{REFERÊNCIAS}

ALMEIDA, Rosemary de O. Mulheres Que Matam. Universo Imaginário do Crime

Feminino. Rio de Janeiro - Relumé - Dumará,

BEHRING, Elaine Rossetti. Fundamentos de política social. In: MOTA, Ana Elisabete [et.al.], (orgs.). Serviço Social e Saúde: formação e trabalho profissional. 2 ed. São Paulo: OPAS, OMS, Ministério da Saúde, 2007.

BRANDÃO, Thadeu. HERMES, Ivenio. Observatório da Violência Letal e Intencional do Rio Grande do Norte feminicídios. Ed. 03, ano II. Natal, 2017.

CAMURÇA, Silvia \& GOUVEIA, Taciana. O Que é Gênero? In: Cadernos SOS Corpo e Cidadania. $4^{\mathrm{a}}$ edição. Recife, PE - SOS Corpo e Cidadania. 2004

CHERNICHARO, Luciana Peluzio. Sobre Mulheres e Prisões: Seletividade de Gênero e Crime de Tráfico de Drogas no Brasil. 2014. Disponível em:

<http://www.neip.info/upd_blob/0001/1565.pdf>. Acesso em 18 de setembro de 2017.

CONECTAS DIREITOS HUMANOS. Mulheres e encarceradas: dupla punição. Disponível em: <http://conectas.org/pt/acoes/justica/noticia/28793-mulheres-e-encarceradas-duplapunicao >. Acesso em 16 de setembro de 2017.

COSTA, Joana. MEDEIROS, Marcelo. O que entendemos por feminização da Pobreza?. Centro Internacional da Pobreza. № 55. Brasília, 2008. Disponível em: <http://www.ipcundp.org/pub/port/IPCOnePager58.pdf>. Acesso em: 28 de agosto de 2017.

COSTA ET al. Joana. A Face Feminina da Pobreza: Sobre Representação e Feminização da Pobreza no Brasil. Brasília, 2005. Disponível em:

$<$ http://www.ipea.gov.br/portal/index.php?option=com_content\&view=article\&id=4726 >. Acesso em 28 de agosto de 2017.

DEL OMO, Rosa. Reclusión de mujeres por delitos de drogas - reflexiones iniciales. Reunión del Grupo de Consulta sobre el Impacto del Abuso de Drogas en la Mujer y la Familia. Organización de los Estados Americanos O.E.A. Montivedéo, Uruguay, 1996. 
ESPINOZA, Olga. A Mulher Encarcerada em Face do Poder Punitivo. São Paulo: IBCCrim, 2004.

GALDINO. Felipe. Mulheres Ganham Espaço no Mundo do Crime e Preocupam Polícia. Novo Notícias. Natal, 2017. < https://www.novonoticias.com/cotidiano/mulheres-ganhamespaco-no-mundo-do-crime-e-preocupam-policia >. Acesso em 11 de setembro de 2017.

HIRATA, Helena. Gênero, classe e raça, Interseccionalidade e consubstancialidade das relações sociais. Revista Tempo Social. V. 26, nº 1. São Paulo, 2014.

<https://www.revistas.usp.br/ts/article/view/84979/87743>. Acesso em 16 de setembro de 2016.

\section{INSTITUTO BRASILEIRO DE GEOGRAFIA E ESTÁTISTICA. Censo Demográfico} Brasileiro 2010: Educação: Amostra. Disponível em:

<http://www.ibge.gov.br/estadosat/temas.php?sigla=rn\&tema=censodemog2010_educ >. acesso em 07 de dezembro de 2016.

\section{INSTITUTO BRASILEIRO DE GEOGRAFIA E ESTÁTISTICA. Censo demográfico}

brasileiro 2010. Sistema Nacional de educação de gênero: análise de resultados. Disponível em: <http://www.ibge.gov.br/estadosat/temas.php?sigla=rn\&tema=censodemog2010_snig >. acesso em 07 de dezembro de 2016.

KARAM, Maria Lucia. Drogas: legislação brasileira e violações a direitos fundamentais, 2010. Disponível em: Rio de Janeiro: LEAP/UFRJ, 2010. KOLLONTAI, A Nova Mulher e a Moral Sexual. 3. ed. São Paulo: Global, 1979.

MARTINS, José de Souza. Exclusão Social e a Nova Desigualdade. 3 ed. São Paulo: Paulos, 1997.

MARX, Karl \& ENGELS, Friedrich. O Manifesto Comunista. $3^{\text {a }}$ edição, São Paulo, Global, 1989.

PIMENTEL. Matheus. O que mudou na Argentina após 1 ano de Maurício Macre. Nexo Jornal. 2016. Disponível em: <https://www.nexojornal.com.br/expresso/2016/12/09/O-que- 
mudou-na-Argentina-ap\%C3\%B3s-1-ano-de-Mauricio-Macri>. Acesso em 16 de setembro de 2017.

RODRIGUES, Paulo Jorge. ET al. O trabalho feminino durante a revolução industrial. XII semana da mulher. São Paulo, 2015. Disponível em:

<https://www.marilia.unesp.br/Home/Eventos/2015/xiisemanadamulher11189/o-trabalhofeminino_paulo-jorge-rodrigues.pdf>. Acesso em 29 de agosto de 2017.

RUFFATO, Luiz. O golpe contra Dilma Roussef. El País. Disponível em: <https://brasil.elpais.com/brasil/2016/08/31/opinion/1472650538_750062.html_. Acesso em: 24 de setembro de 2017.

\section{SECRETARIA DE ESTADO DE SEGURANÇA PÚBLICA E DA DEFESA SOCIAL.}

\section{Relatório Estatítico de Crimes Violentos Letais e Intencionais de Janeiro a Junnho de} 2017. Natal, 2017.

SILVA, Sabrina de Lima. Dupla punição: Mulheres Encarceradas por Delito de Tráfico de Drogas. Monografia. Natal: UFRN, 2015.

SANDENBERG, Cecília M.B. Conceituando "emponderamento" na perspectiva feminista. I Seminário Internacional: Trilhas do Empoderamento de Mulheres - Projeto TEMPO, Salvador: UFBA, 2009. Disponível em: $<$ https://repositorio.ufba.br/ri/bitstream/ri/6848/1/Conceituando\%20Empoderamento\%20na\% 20Perspectiva\%20Feminista.pdf> Acesso em: 29 de agosto de 2017.

WAISELFSZ, Julio Jacobo. Mapa da Violência 2016 Homicídios Por Arma de Fogo no Brasil. Brasília. Flacso, 2016. 
WOMEN AND CRIMINALITY: ASPECTS OF SKEWED INCLUSION

\begin{abstract}
In the State of Rio Grande do Norte, there was a $28 \%$ increase in the number of women murdered due to involvement in illicit conduct in the period from January to June of 2017 compared to the same period last year. This phenomenon encourages us to investigate what would be the main causes for the growing number of femicides in the State, establishing a counterpoint between gender and crime, evaluating the first half of the current year.
\end{abstract}

Keywords: Femicide. Gender inequality. Crime. 